\title{
Papel da óxido nítrico sintase na etiopatogenia da estenose hipertrófica do piloro na infância
}

\author{
Role of nitric oxide synthase in the etiopathogenesis of hypertrophic pyloric stenosis in infants
}

\author{
Irnak M. Barbosa ${ }^{1}$, Saulo M.R. Ferrante ${ }^{2}$, Carlos A. Mandarim-de-Lacerda ${ }^{3}$
}

\section{Resumo}

Objetivos: reproduzir, experimentalmente, em ratos, por meio do inibidor da enzima óxido nítrico sintase (ONS - L-NAME), os achados histopatológicos correspondentes a estenose hipertrófica do piloro da infância (EHPI).

Métodos: para reproduzir o modelo de inibição de ONS na produção de EHPI, administrou-se L-NAME em ratas grávidas, a partir do $14^{\circ}$ dia gestacional (grupo L-NAME), comparando-se com uma gestação de controle. Após o nascimento, todos os ratos do grupo L-NAME foram mantidos sob inibição da ONS até o $42^{\circ}$ dia de vida, quando foram sacrificados. Os filhotes da gestação de controle, em que nenhuma droga foi administrada, foram também sacrificados com 42 dias de vida. Os animais e as vísceras foram analisados e pesados. A região pilórica foi preparada tecnicamente e observada em microscopia de luz.

Resultados: em comparação com os animais de controle, os LNAME tiveram peso corporal e intestinal menor e peso gástrico maior. Nos animais L-NAME a microscopia de luz evidenciou hipertrofia da camada circular do músculo liso do piloro.

Conclusão: este trabalho reproduziu um modelo experimental de estudo da estenose hipertrófica do piloro e comprovou, neste modelo, a associação da ausência da ON sintase na musculatura do piloro.

J Pediatr (Rio J) 2001; 77 (4): 307-12: estenose pilórica, óxidos de nitrogênio, L-NAME.

\section{Introdução}

A estenose hipertrófica do piloro na infância (EHPI) é uma afecção comum, com incidência de $0,3 \%$ em recémnatos. Ocorre, preferentemente, entre as $3^{\mathrm{a}}$ e $6^{\mathrm{a}}$ semanas de vida, caracterizada pela hipertrofia da camada circular da musculatura do piloro, evoluindo com obstrução pilórica e persistência de vômitos.

1. Mestre em Cirurgia Pediátrica.

2. Professor Adjunto, Depto. de Cirurgia, Disciplina de Cirurgia Pediátrica, Faculdade de Medicina da Universidade Federal do Rio de Janeiro.

3. Professor Titular, Laboratório de Morfometria, Centro Biomédico, Universidade do Estado do Rio de Janeiro.

\begin{abstract}
Objective: to experimentally reproduce, in rats, the findings corresponding to the histopathology of infantile hypertrophic pyloric stenosis (IHSP), using nitric oxide synthase (NOS) inhibitor (L-NAME).

Methods: L-NAME was administered to pregnant rats (LNAME group), from the 14th gestational day on in order to reproduce the model of NOS inhibition in the production of IHSP. This group was then compared to control animals. After birth, all the animals in the L-NAME group were maintained under NOS inhibition until the 42nd day of life, when they were sacrificed. The control animals, which did not receive any kind of drug, were also sacrificed on the 42nd day of life. The animals and their internal organs were analyzed and weighed. The pyloric region was technically prepared and observed through light microscopy.

Results: the L-NAME group presented lower body and intestinal weight and higher gastric weight than the control group. Light microscopy revealed hypertrophy of the circular smooth muscle layer of the pyloric muscle in L-NAME animals.

Conclusions: this work reproduced an experimental model of an IHSP study, confirming the effect of NOS blockade on the pyloric musculature.
\end{abstract}

J Pediatr (Rio J) 2001; 77 (4): 307-12: pyloric stenosis, nitric oxide synthase, L-NAME.

A etiologia da EHPI, até o momento, não foi completamente elucidada. Acredita-se que haja uma associação de fatores hereditários e ambientais. Várias teorias têm sido propostas, envolvendo a inervação do piloro, o controle hormonal, as proteínas da matriz extracelular, as inervações peptidérgica e nitrérgica e, recentemente, as alterações nos fatores de crescimento da musculatura lisa ${ }^{1,2}$. Acredita-se, hoje, que alterações primárias da inervação do sistema nervoso entérico, associadas à ausência de ONS e células intersticiais de $\mathrm{Cajal}^{3}$, sejam teorias mais promissoras para explicar a fisiopatologia da EHPI. 
Recentes trabalhos têm demonstrado que o óxido nítrico (ON) é uma substância instável cuja formação é catalisada pela ONS a partir da L-arginina ${ }^{4}$, sendo um dos principais responsáveis pelo relaxamento da musculatura lisa do trato gastrintestinal. A isoforma neuronal da ONS é encontrada tanto no sistema nervoso central como no sistema nervoso periférico ${ }^{5}$. No trato gastrintestinal, há atividade da ONS, detectada por imuno-histoquímica no plexo mientérico e nos planos musculares (circular e longitudinal). Huang et al. ${ }^{6}$ conseguiram, por recombinação genética, desenvolver uma raça mutante de ratos com alteração do locus do gene da ONS que têm ausência da atividade desta enzima e presença de hipertrofia da camada circular da musculatura do piloro com aumento do tamanho do estôma$\mathrm{go}^{7}$.

Este trabalho tem o objetivo de reproduzir experimentalmente os achados histopatológicos correspondentes à EHPI quando há inibição da síntese do ON.

\section{Materiais e métodos}

O presente trabalho usou ratos Wistar provenientes do biotério central da Fiocruz/RJ. Três fêmeas grávidas, a primeira com 14 dias de gestação e as outras com 16 dias de gestação, foram denominadas, D14 e D16 (grupo com bloqueador da ONS) e D16c (grupo controle). Até o final da gestação, permaneceram no biotério do Laboratório de Morfometria da UERJ, sob condições controladas de temperatura, iluminação e umidade ambiental, sendo alimentados com ração própria para rato $\left(\mathrm{Nuvilab}^{\circledR}\right)$ e recebendo água potável ad libitum.

Entre o início do trabalho e o final da gestação, as ratas D14 e D16 receberam o bloqueador da óxido-nítricosintase L-NAME (hidrocloreto de $\mathrm{N}^{\mathrm{w}}$ Nitro-L-Arginina Metil Éster, Sigma Chemical Co., St. Louis, Lote 98H1427), na dose $50 \mathrm{mg} / \mathrm{kg} / \mathrm{dia}$, dissolvidos na água do bebedouro, oferecida na quantidade mínima diária suficiente. Não houve uma diferença significativa do volume de água ingerida entre os animais. À rata D16c não foi oferecido o L-NAME, sendo considerada o animal controle.

As ninhadas D14, D16 e D16c foram constituídas, respectivamente, de sete, seis e cinco filhotes. No $21^{\circ}$ dia de vida, os filhotes foram separados das mães, pesados e acompanhados por mais 21 dias, quando foram sacrificados. Neste período que se seguiu ao desmame, todos os filhotes continuaram sendo alimentados com a mesma dieta que, até o desmame, vinha sendo oferecida às suas respectivas mães. O L-NAME foi oferecido aos filhotes D14 e D16 (mas não aos D16c) na água do bebedouro, por mais 21 dias, na dose de $50 \mathrm{mg} / \mathrm{kg} / \mathrm{dia}$.

Com 42 dias de vida, os animais foram sacrificados por inalação de éter sulfúrico e injeção intracardíaca de cerca de $0,5 \mathrm{ml}$ de $\mathrm{KCl}$, sendo retirados o estômago, o piloro e o intestino delgado, que foram medidos e pesados. O intestino (do duodeno à válvula ileocecal) foi removido, limpo do material intestinal e medido. Em seguida, fragmentos compreendendo toda a extensão da parede da região pilórica foram fixados em solução tamponada de formol $10 \%$, à temperatura ambiente, por 48 horas. Depois, foram incluídos em parafina e seccionados com $3 \mathrm{~mm}$ e $10 \mu \mathrm{m}$ de espessura. Os cortes foram preparados tecnicamente e corados com hematoxilina-eosina e tricrômico de Masson.

Foi calculada a estatística descritiva. As diferenças entre os grupos foram testadas com o teste não paramétrico de Mann-Whitney com índice de significância de 0,05.

\section{Resultados}

Os grupos foram analisados quanto ao peso dos filhotes. A comparação do peso no $21^{\circ}$ dia de vida dos grupos LNAME (D14 e D16) e grupo controle (D16c) não foi significativa (Figura 1). Esta comparação no $42^{\circ}$ dia de vida mostra uma diferença significativa no ganho do peso corporal entre os grupos L-NAME e grupo controle (Figura 2). Observam-se os valores do peso e dimensão das estruturas que foram retiradas dos 18 filhotes. Considerando a média \pm desvio padrão, o comprimento do intestino delgado teve valores de $90,72 \pm 5,89 \mathrm{~cm}$, o peso do estômago teve $1,50 \pm 0,27 \mathrm{~g}$. Nos grupos L-NAME (D14,D16) a média do peso do estômago foi maior que no controle.

Figura 1 - Gráfico em barras (média \pm desvio-padrão) do peso corporal no $21^{\circ}$ dia pós-natal dos grupos D16 (LNAME) e D16c (controle)

A discrepância da relação do peso do estômago em comparação com o peso corporal nos grupos L-NAME e controle foi estatisticamente significativa (Figura 3). O peso do intestino teve valores de $7,20 \pm 0,87 \mathrm{~g}$. A relação do peso e comprimento do intestino delgado, entre os grupos L-NAME e controle, mostrou-se também significativa (Figura 4). 
tivamente. Esta discussão foi iniciada por Belding e Kernohan $^{8}$ quando afirmaram que havia, nos pacientes com EHPI, uma diminuição do número de células ganglionares e fibras neurais, por um processo degenerativo, que foram, posteriomente, confirmados por Sptiz e Kaufmann ${ }^{9}$.

Friesen e Boley ${ }^{10}$, após análise comparativa das células neurais de crianças com EHPI e fetos normais, propuseram a teoria da imaturidade das células ganglionares em pacientes com EHPI. Posteriormente, outros autores observaram alterações nas terminações neurais no piloro ${ }^{11} \mathrm{e}$ nas células de suporte neural ${ }^{12}$, além de alterações ultra-estruturais no plexo mientérico e músculo do piloro.

Figura 2 - Gráfico em barras (média \pm desvio-padrão) do peso corporal no $42^{\circ}$ dia pós-natal dos grupos D16 (LNAME) e D16c (controle)

A avaliação histológica da musculatura circular do piloro, nos 13 filhotes que receberam L-NAME, demonstrou uma diferença significativa da espessura do piloro. A hipertrofia da camada muscular do piloro ficou caracterizada no corte longitudinal com a medida do maior diâmetro, sendo duas vezes o valor da espessura do piloro do grupo de controle (Figura 5).

\section{Discussão}

A etiologia da EHPI permanece desconhecida, apesar do avanço da biologia molecular e da engenharia genética. Os estudos mais recentes apontam para alterações no SNE nos pacientes com EHPI, tanto quantitativa quanto qualita-

Figura 3 - Gráfico em barras (média \pm desvio-padrão) da relação peso do estômago/peso corporal dos ratos sacrificados dos grupos D16 (L-NAME) e D16c (controle)

Tabela 1 - Média do peso dos filhotes e vísceras

\begin{tabular}{lllll}
\hline Variável & D14 (n=7) & D16 (n=6) & D16c $(\mathbf{n = 5})$ & $\mathbf{p}^{\ddagger}$ \\
\hline Peso $\left( \pm \mathrm{dp}^{*}, \mathrm{~g}^{\dagger}\right)$ aos 21 dias & $29 \pm 2,62$ & $53,6 \pm 4,26$ & $59,3 \pm 5,35$ & 0,06 \\
Peso $( \pm \mathrm{dp}, \mathrm{g})$ aos 42 dias & $77,4 \pm 9,83$ & $144,6 \pm 23,07$ & $168,8 \pm 27,52$ & 0,04 \\
Peso do intestino delgado $( \pm \mathrm{dp}, \mathrm{g})$ & $6,504 \pm 0,84$ & $6,035 \pm 0,28$ & $8,160 \pm 0,24$ & 0,006 \\
Peso do estômago $( \pm \mathrm{dp}, \mathrm{g})$ & $1,504 \pm 0,27$ & $1,691 \pm 0,20$ & $1,250 \pm 0,08$ & 0,006 \\
\hline
\end{tabular}

* desvio padrão; †: grama; †: índice de significância $(p<0,05)$, teste não paramétrico de Mann-Whitney 
Figura 4 - Gráfico em barras (média \pm desvio-padrão) da relação peso/comprimento do intestino delgado dos ratos sacrificados dos grupos D16 (L-NAME) e D16c (controle)

Novas técnicas identificaram peptídeos gastrintestinais e descreveram com maior detalhe a inervação peptidérgica. Malmfors e Sandler ${ }^{1}$ descreveram alterações na inervação peptidérgica, demonstrando a diminuição de fibras neurais específicas para o peptídeo vaso-ativo intestinal (VIP), a substância $\mathrm{P}$ e a encefalina, em pacientes com EHPI. O VIP é encontrado em altas concentrações no piloro, estando envolvido no relaxamento da musculatura lisa do trato gastrintestinal e sendo, provavelmente, um dos elementos responsáveis pelo controle do mecanismo esfincteriano do piloro $^{13}$. Grider ${ }^{14}$ demonstrou a existência de uma ação sinérgica entre o VIP e o ON, analisando, in vitro, fibras musculares lisas do piloro e concluindo, assim, que o VIP estimula a produção de ON. O relaxamento das fibras musculares lisas é mantido e amplificado pelo VIP, liberado na junção pré-sináptica por estímulo do ON, que também age na fase inicial deste relaxamento.

Barajas-Lopez ${ }^{15}$ e Serio ${ }^{16}$ comprovaram que as células intersticiais de Cajal funcionam como marcapassos reguladores do impulso elétrico da musculatura lisa intestinal. Langer $^{3}$ observou a diminuição do número de células intersticiais de Cajal em pacientes com EHPI, o que foi confirmado utilizando o método imunoistoquímico para pesquisa de receptores transmembrana tirosina-quinase $(\mathrm{C}$ $\mathrm{KIT}$ ), específico para pesquisa de células intersticiais de Cajal no trato gastrintestinal ${ }^{17}$.

O ON, inicialmente identificado como fator de relaxamento derivado do endotélio (EDRF) ${ }^{18,19}$, é reconhecido como um potente neurotransmissor não colinérgico e não adrenérgico, envolvido na inervação inibitória da musculatura lisa do trato gastrintestinal ${ }^{5,20}$. Em pacientes com EHPI, observou-se a ausêrncia da NADPH diaforase (enzima considerada, no SNC e SNP, como sendo a própria ONS). Biópsias de segmentos da musculatura do piloro em crianças com EHPI apresentaram ONS diminuída nas fibras neurais da camada circular do piloro, com preservação dessa enzima no plexo mientérico ${ }^{21,22}$. Ratos mutagênicos (knockout), com ausência da ONS, são férteis, sem qualquer alteração no SNC, mas apresentam estômago aumentado de tamanho com hipertrofia da camada circular da musculatura do piloro ${ }^{6}$. Kusafuka e Puri ${ }^{23}$ demonstraram níveis mais baixos de RNA mensageiro da ONS neuronal na musculatura do piloro dos pacientes com EHPI.
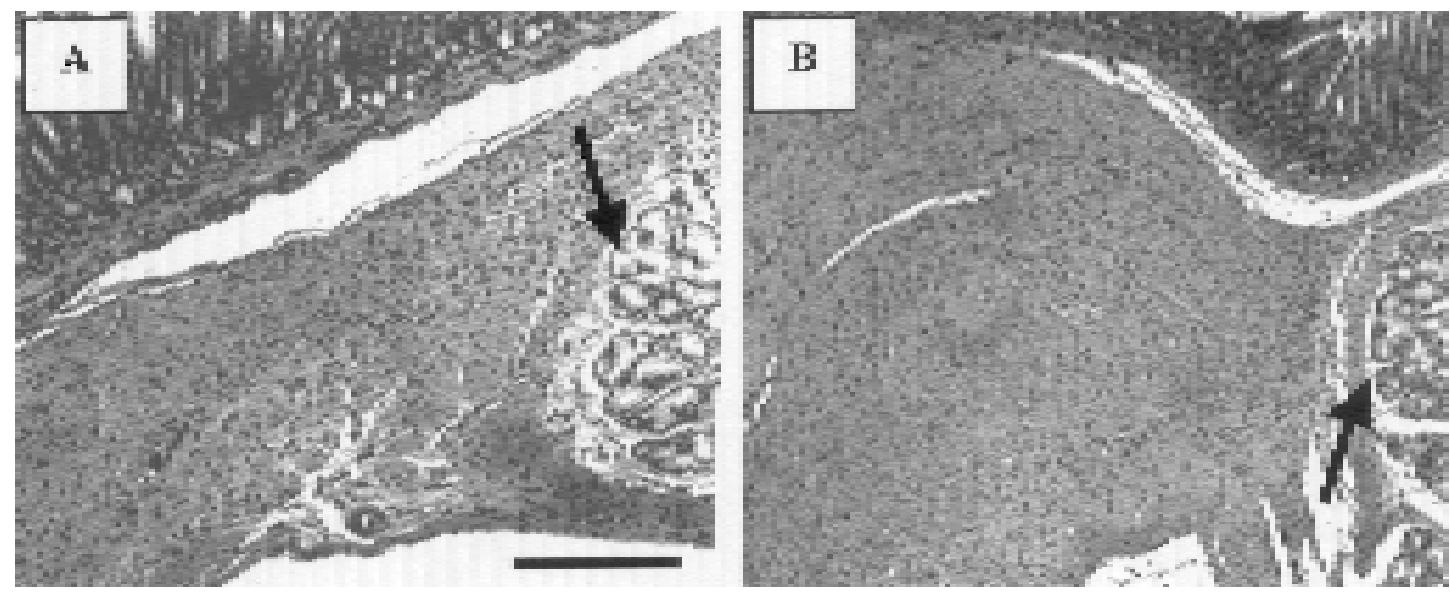

Figura 5 - Fotomicrografias da região pilórica do rato (coloração: tricrômico de Masson, barra: 0,2mm). Transição piloro-duodenal em animais controle (A) e em animais L-NAME (B). As setas indicam o início do duodeno (glândulas de Brünner) 
A formação de ON está aumentada na gravidez, explicando a vasodilatação materna neste período. A utilização de bloqueador da ONS no final da gestação, em ratos, não afetou a saúde da mãe, mas afetou a prole, com retardo do crescimento intra-uterino e alterações isquêmicas, com o não desenvolvimento de membros nos fetos ${ }^{25,26}$. Além disso, observou-se também retardo do crescimento no período neonatal dos ratos inibidos com L-NAME, associado ao aumento do tamanho do estômago, diminuição do peso do intestino e hipertrofia da camada muscular do piloro. A comparação do peso do cérebro em relação às vísceras revelou a desnutrição desses ratos que receberam L-NAME, decorrente à obstrução pilórica ${ }^{26}$.

No presente estudo, observou-se que os animais ganharam peso entre o período do desmame ( $21^{\circ}$ dia de vida) e o dia do sacrifício $\left(42^{\circ}\right.$ dia de vida), o que pode ser explicado pelo efeito tardio da inibição da ONS e pela transição da dieta líquida (leite materno) para sólida (ração). O aumento do peso do estômago e a diminuição do peso do intestino delgado, associados à hipertrofia da camada circular da musculatura do piloro, confirmaram os achados de Voelker e colaboradores ${ }^{26}$.

Os resultados deste trabalho reforçam a teoria que tenta explicar a fisiopatologia da EHPI como consequiência da ausência, no piloro, do neurotransmissor não adrenérgico e não colinérgico, descrito por Furchgott ${ }^{18} \mathrm{e}$ Ignarro ${ }^{19}$ como óxido nítrico $(\mathrm{ON})$. Vanderwinden ${ }^{21}$ foi pioneiro na associação da ausência da ONS e EHPI, que foi confirmada depois $6,22,23$. A regularização da inervação do piloro e da atividade da ONS, em pacientes que tiveram tratamento cirúrgico, sugere que esta ausência da ONS, nos pacientes com EHPI, é de caráter transitório.

Embora estudos específicos sejam indispensáveis para dimensionar a importância do ON na etiopatogenia da EHPI, este trabalho sugere que o bloqueio da síntese do ON, levando à perda da ação relaxante da musculatura lisa intestinal, é um elemento central deste processo.

\section{Referências bibliográficas}

1. Malmfors G, Sundler F. Peptidergic innervation in infantile hypertrophic pyloric stenosis. J Pediatric Surg 1986; 21:303-6.

2. Ohshiro K, Puri P. Pathogenesis of infantile hypertrophic pyloric stenosis: recent progress. Pediatr Surg Int 1998;13:243-52.

3. Langer J, Berezin I, Daniel EE. Hypertrophic pyloric stenosis: ultrastructural abnormalities of enteric nerves and the interstitial cells of Cajal. J Pediatr Surg 1995;30:1535-43.

4. Levebvre RA. Nitric oxide in the peripheral nervous system. Ann Med 1995;27:379-88.

5. Snyder SH, Bredt DS. Nitric oxide as a neuronal messenger. Trends Pharmacol Sci 1991; 12:125-8.
6. Huang PL, Dawson TM, Bredt DS, Snyder SH, Fishman MC. Targeted disruption of the neuronal nitric oxide synthase gene. Cell 1993; 75:1273-86.

7. Chung E, Curtis D, Chen G, Marsden PA, Twells R, Xu W, et al. Genetic evidence for the neuronal nitric oxide synthase gene (NOS1) as a susceptibility locus for infantile pyloric stenosis. Am J Hum Genet 1996; 58:363-370.

8. Belding HH, Kernohan JW. A morphologic study of the myenteric plexus and musculature of the pylorus with special reference to the changes in hypertrophic pyloric stenosis. Surg Gynecol Obstet 1953; 97:322-8.

9. Sptiz L, Kaufmann JCE. The Neuropathological changes in congenital hypertrophic pyloric stenosis. South African J Surg $1975 ; 13: 239-42$.

10. Friesen SR, Boley JO, Miller DR. The myenteric plexus of the pylorus: its early normal development and its changes in hypertrophic pyloric stenosis. Surgery 1956; 39:21-29.

11. Okazaki T, Yamataka A, Fujiwara T, Nishiye H, Fujimoto T, Miyano T. Abnormal distribution of nerve terminals in infantile hypertrophic pyloric stenosis. J Pediatr Surg 1994; 29:655-8.

12. Kobayashi H, Briain DSO, Puri P. Selective reduction in intramuscular nerve supporting cells in infantile hypertrophic pyloric stenosis. J Pediatr Surg 1994; 29:651-4.

13. D $\notin$ Amato M, Beurme FAD, Lefebvre RA. Comparison of the effect of vasoactive intestinal polypeptide and non-adrenergic non-cholinergic neurone stimulation in the cat gastric fundus. Eur J Pharmacol 1988;152:71-82.

14. Grider JR, Murthy KS, Jin JG, Makhlouf GM. Stimulation of nitric oxide from muscle cells by VIP: prejunctional enhancement of VIP release. Am J Physiol 1992;262:G774-G778.

15. Barajas-Lopez C, Berezin I, Daniel EE, Huizinga JD. Pacemaker activity recorded in interstitial cells of Cajal of the gastrointestinal tract. Am J Physiol 1989; 257:C830-C835.

16. Serio R, Barajas-Lopez C, Daniel EE, Berezin I, Huizinga JD. Slow-wave activity in colon: role of network of submucosal interstitial cells of Cajal. Am J Physiol 1991; 260:G636-G645.

17. Vanderwinden JM, Liu H, Laet MHD, Vanderhaeghen JJ. Study of interstitial cells of Cajal in infantile hypertrophic pyloric stenosis. Gastroenterol 1996; 111:279-88.

18. Furchgott RF, Zawadzki JV. The obligatory role of endothelial cells in the relaxation of arterial smooth muscle by acetylcholine. Nature 1980; 228:373-6.

19. Ignarro LJ, Harbison RG, Wood KS, Kadowitz PJ. Activation of purified soluble guanylate cyclase by endothelium derived relaxing factor from intrapulmonary bradykinin and arachidonic acid. J Pharmacol Exp Ther 1986; 237:893-900.

20. Snyder SH, Brendt DS. Biological roles of nitric oxide. Sci Am 1992;28-35.

21. Vanderwinden JM, Mailleux P, Schiffmann SN, Vanderhaeghen JJ, Laet MHD. Nitric oxide synthase activity in infantile hypertrophic pyloric stenosis. N Engl J Med 1992;327:511-15.

22. Kobayashi H, O`Briain DS, Puri P. Immunochemical characterization of neural cell adhesion molecule (NCAM), nitric oxide synthase, and neurofilament protein expression in pyloric muscle of patients with pyloric stenosis. J Pediatr Gastroenterol Nutr $1995 ; 20: 319-25$.

23. Kusafuka T, Puri P. Altered messenger RNA expression of the neuronal nitric oxide synthase gene in infantile hypertrophic pyloric stenosis. Pediatr Surg Int 1997;12:576-79.

24. Conrad KP, Joffe GM, Kruszyna H, Kruszyna R, Rochelle LG, Smith RP, et al. Identification of increased nitric oxide biosynthesis during pregnancy in rats. FASEB J 1993; 7:566-571. 
25. Nitric oxide inhibition causes intrauterine growth retardation and hind-limb disruptions in rats. Am J Obstet Gynecol 1994; 171:1243-50.

26. Voelker CA, Miller MJS, Zhang XJ, Clark SECDA, Pierce MR. Perinatal nitric oxide synthase inhibition retards neonatal growth by inducing hypertrophic pyloric Stenosis in rats. Pediatric Research 1995; 38:768-74.

27. Ludtke FE, Bertus M, Voth E, Michalski S, Lepsien G. Gastric emptying 16 to 26 years after treatment of infantile hypertrophic pyloric stenosis. J Pediatr Surg 1994;29:523-26.
28. Vanderwinden JM, Liu H, Menu R, Conreur JL, Laet MHDL, Vanderhaeghen JJ. The pathology of infantile hypertrophic pyloric stenosis after healing. J Pediatr Surg 1996; 11:1530-4.

Endereço para correspondência:

Dr. Irnak Marcelo Barbosa

Rua General Osório, 109/302

CEP 28625-630 - Nova Friburgo, RJ 